\title{
Kavinia chacoserrana sp. nov. (Gomphales, Basidiomycota): a new species from South America based on morphological and molecular data
}

\author{
Robledo GL ${ }^{1,2^{*}}$ and Urcelay $C^{1}$ \\ ${ }^{1}$ Instituto Multidisciplinario de Biología Vegetal, Universidad Nacional de Córdoba, C.C.495, 5000, Córdoba, \\ Argentina. \\ ${ }^{2}$ Fundación FungiCosmos, Av. General Paz 154, 4ㅇ, Of. 4, CP 5000, Córdoba, Argentina.
}

Robledo GL, Urcelay C 2017 - Kavinia chacoserrana sp. nov. (Gomphales, Basidiomycota): a new species from South America based on morphological and molecular data. Mycosphere 8(8), 1028 1034, Doi 10.5943/mycosphere/8/6/3

\begin{abstract}
Kavinia chacoserrana is described as a new species based on morphological data and molecular evidence. The species is characterized by its white to pale yellowish hydnoid hymenophore and cylindrical to fusiform basidiospores measured as 10-12 × 3-4 $\mu \mathrm{m}$. Phylogenetic analysis provide evidence suggesting that, as currently accepted, Kavinia alboviridis is a species complex.
\end{abstract}

Key words - Argentina - Chaco - corticioid fungi - neotropical fungi - phylogeny - taxonomy

\section{Introduction}

Kavinia Pilát is a small genus belonging to the Gomphales (Giachini et al. 2010) typifed by $K$. sajanensis (Pilát) Pilát (=Kavinia alboviridis (Morgan) Gilb. \& Budington). Up to now includes four species characterized by annual resupinate and hydnoid basidiocarps, a monomitic hyphal structure with clamp connections, and oblong, subcylindrical or fusiform and non-amyloid basidiospores bearing cyanophilous warts (Eriksson \& Ryvarden 1976, Boidin \& Gilles 2000).

Three species are known from only from their type locations, all in the tropics: Kavinia globispora Natarajan \& Koland. from southern India (Natarajan \& Kolandavelu 1985), K. salmonea Boidin \& Gilles from the Reunion Island in the pacific (Boidin \& Gilles 2000), and K. vivantii Boidin \& Gilles in Marie Galante Island in the Caribe (Boidin \& Gilles 2000). In notorious contrast, the fourth species of Kavinia, K. alboviridis, is widely distributed in both hemispheres, mainly in temperate regions such as North America (e.g. Gilbertson \& Budington 1970), Europe (e.g. Eriksson \& Ryvarden 1976, Boidin \& Gilles 2000, Kout \& Hajšmanová 2015), Turkey (Doğan 2009), central China (Maekawa \& Zang 2002, Dai 2011), Northern India (Rattan 1977) and southern South America (Greslebin 2002), but also in some tropical regions such as Ethiopia in Africa (Bitew \& Ryvarden 2011). Despite its wide distribution, $K$. alboviridis is not a common species and it has been suggested that more than one species is involved under this name (Kout \& Hajšmanová 2015).

Here we describe a new species from central Argentina, subtropical Chaquean region in South America based on morphological and molecular evidence, and provide phylogenetic evidence that, as currently accepted, Kavinia alboviridis is a complex of species. 


\section{Materials \& Methods}

\section{Morphological studies}

The studied specimens were deposited in the herbarium CORD. Herbarium acronyms follow Thiers (2017). Basidiomata sections were examined in Melzer's reagent, KOH 3-5\% plus phloxine $1 \%$. Microscopic measurements of basidiospores $(n=40)$ were made in Melzer's reagent, $5 \%$ of the measurements were excluded from each end and are given in parentheses. The following abbreviations are used for basidiospores measurements: $\bar{X}=$ arithmetic average, $Q$ = ratio length/width, $\bar{Q}=$ arithmetic average of $Q$.

\section{DNA extraction and sequencing}

DNA was extracted from dry basidiomata tissue using the CTAB method described in FerreiraLopes et al. (2016). Primer pairs ITS8-F / ITS6-R (Dentinger et al. 2010) to amplify ITS rDNA. PCR conditions were as described in Gómez-Montoya et al. (2017). Sequencing reactions were performed with the same primers pairs.

\section{Phylogenetic analyses}

Sequences of nrITS of Gomphales were selected following reference phylogenetic works (Giachini et al. 2010, Chen et al. 2015), retrieved from GenBank (NCBI) and combined to construct a dataset matrix (Table 1). The dataset was aligned using MAFFT v.7 (Katoh \& Standley 2013), under the G-INS-1 or Q-INS-i criteria. The alignment obtained, was then manually inspected using MEGA v.6 (Tamura et al. 2013), and then deposited at TreeBase (Submission ID 21247). The bestfit model of nucleotide evolution to the dataset was selected by AIC (Akaike Information Criterion) using jModelTest2 v.1.6 (Darriba et al. 2012). Bayesian Inference (BI) was performed using MrBayes 3.1.2 (Ronquist et al. 2011) with two independent runs, each one beginning from random trees with four simultaneous independent chains, performing 1x107 replications, sampling one tree every $1 \times 103$ th generation. The first 2500 sampled trees were discarded as burn-in and checked by the convergence criterion (frequencies of average standard deviation of split $<0.01$ ), while the remaining ones were used to reconstruct a 50\% majority-rule consensus tree and calculate Bayesian posterior probabilities (BPP) of the clades. Nodes showing BPP $\geq 0.95$ was considered to be strongly supported, while those with values BPP $\geq 0.85$ were considered moderately supported.

Table 1 List of taxa, specimens and sequences used in the phylogenetic analysis. $\mathbf{O}=$ outgroup.

\begin{tabular}{lc}
\hline $\begin{array}{l}\text { Species } \\
\text { Voucher reference - Origin }\end{array}$ & ITS Genbank Accesion No \\
\hline Ramaria suecica $(\mathbf{O})$ & \\
OSC 115933-USA: OR, Linn County & KP658148 \\
OSC 134634-USA: OR & JX310417 \\
Clavariadelphus occidentalis & \\
OSC 114281, USA & EU846242 \\
OSC 104664, USA & EU669308 \\
H21536, Tunisia & KU973835 \\
Clavariadelphus pistillaris & \\
3894, Canada, Quebec & KM248917 \\
Clavariadelphus truncatus & \\
SMI278, Canada, British Columbia & HQ650728 \\
Lentaria bambusina & \\
MHHNU 7302, Liuyang, Hunan, China & KU324496 \\
MHHNU 6794, Sangzhi, Hunan, China & KU870448 \\
Lentaria byssisseda &
\end{tabular}


TENN61159, USA, TN

FJ596785

Lentaria. aff. micheneri

MA-Fungi 48116 Equatorial Guinea

AJ292289

Lentaria patouillardii

MHHNU 7829, China: Baihaba, Xinjiang

KU324498

HMJAU:26892, China: Inner Mongolia

KU870449

MA-Fungi 48032, Spain

AJ292290

Lentaria surculus

PDD 95856, Mid Canterbury, New Zealand

HQ533048

MHHNU 8721 Xishuangbanna, Yunnan, China

KU870450

FHMU 880 Dinghushan, Guangdong, China

KU870451

Hydnocristella himantia

CFMR:DLL2011-079, USA: central Wisconsin

KJ140598

2543, Russia

KY769580

CFMR:DLL2011-131, , USA: central Wisconsin

KJ140634

Yuan5598, China

KP323407

MA-Fungi 48091, SPAIN

AJ292291

Hydnocristella latihpha

He 20120911-3 China, Jiuzhaigou Nature Reserve

KM489521

He 20120914-4 China, Jiuzhaigou Nature Reserve

KM489522

Kavinia alboviridis

KM82737, England

GQ981505

KM141510, England

GQ981506

UC2022816, USA: AK

KP814530

Kavinia chacoserrana

Robledo 2516, Argentina

MF377531

Ramaria rubella

OSC 115946, USA

EU669317

OSC 140659, USA

JX310405

AFTOL-ID 724

NR119527

Ramaria pinicola

TENN 29617, USA: ID, Upper Priest River County

KX574473

139.1, USA

DQ365649

Ramaria sp.

OSC 65995, USA

DQ365600

Ramaria stricta

OUC97191, Canada?

DQ367910

\section{Results}

\section{Phylogenetic analyses}

The final nrITS dataset included sequences from 35 specimens, with 621 characters including gaps, of which 270 are conserved and 286 parsimony informative. The evolutionary model selected for nrITS dataset was GTR+I+G.

Our analysis (Fig. 1) recovered Kavinia as a well-supported clade (BS = 1) where Kavinia chacoserrana emerged a distinct lineage. Kavinia chacoserrana grouped with a specimen identified as Kavinia aff. alboviridis in a moderately supported clade (BS $=0.87)$. Two specimens identified as $K$. alboviridis, the type species of Kavinia, appear as a third taxon integrating the clade.

Kavinia chacoserrana Robledo \& Urcelay, sp. nov.

Figs $2-5$

Mycobank: MB821874; Facesoffungi number: FoF03450 
Type - Argentina, Córdoba, Dpto. San Alberto, Los Hornillos, on dead fallen branch of Lithraea molleoides, 31 ${ }^{\circ} 54^{\prime} 0.8^{\prime \prime S}, 64^{\circ} 58^{\prime \prime} 0.6 " \mathrm{~W}, 1280$ m a.s.1., 28 Apr 2012 Robledo 2516 (CORD holotype, ITS MF377531).

Etymology - Referring to the ecoregion where it was collected, Chaco Serrano.

Basidiomata seasonal, resupinate, loosely attached, arising from the substrate in several surrounding points and then confluent with development. Hymenophore hydnoid, with spines up to $10 \mathrm{~mm}$ long, about $3 \mathrm{~mm}$ diam at the base slimming gradually to end in a sharp apex, white when immature, pale yellowish at maturity. Margin sterile, whitish, myceliar, with rizhomorphic strands. Subiculum whitish, loose, extremely thin. Hyphal system monomitic. Generative hyphae with clamps, ampuliform clamps occasionally observed, hyaline and thin-walled to very slightly thickwalled, up to $5 \mu \mathrm{m}$ diam; hyphae parallel ordered and compact in the trama of spines, loosely interwoven in the subiculum. Cystidia absent. Basidia clavate, 30-40 long, 5-6 (-12) $\mu \mathrm{m}$ in the apex with four sterigmata and 2-3 $\mu \mathrm{m}$ at the base where present a basal clamp. Hymenium not reaching the apex of the spine which is sterile. Basidiospores cylindrical to fusiform in side view, with a distinctly supra-apicular concavity and a tapering to rounded apex (Fig. 5); in dorsi-ventral view cylindrical to subcylindrical and then ovoid to slightly ellipsoid (Fig. 5), (9.0-)10.0-12.0(-13.0) $\times$ $(2.5-) 3.0-4.0(-4.0) \mu \mathrm{m},(\bar{X}=10.7 \times 3.3 \mu \mathrm{m}), Q=2.5-4.2,(\bar{Q}=3.3)$, slightly thick-walled, hyaline to pale yellowish, warted, IKI-, CB-; commonly grouped in tetrads (Fig. 5 black arrows).

Known distribution - So far known only from the type locality.

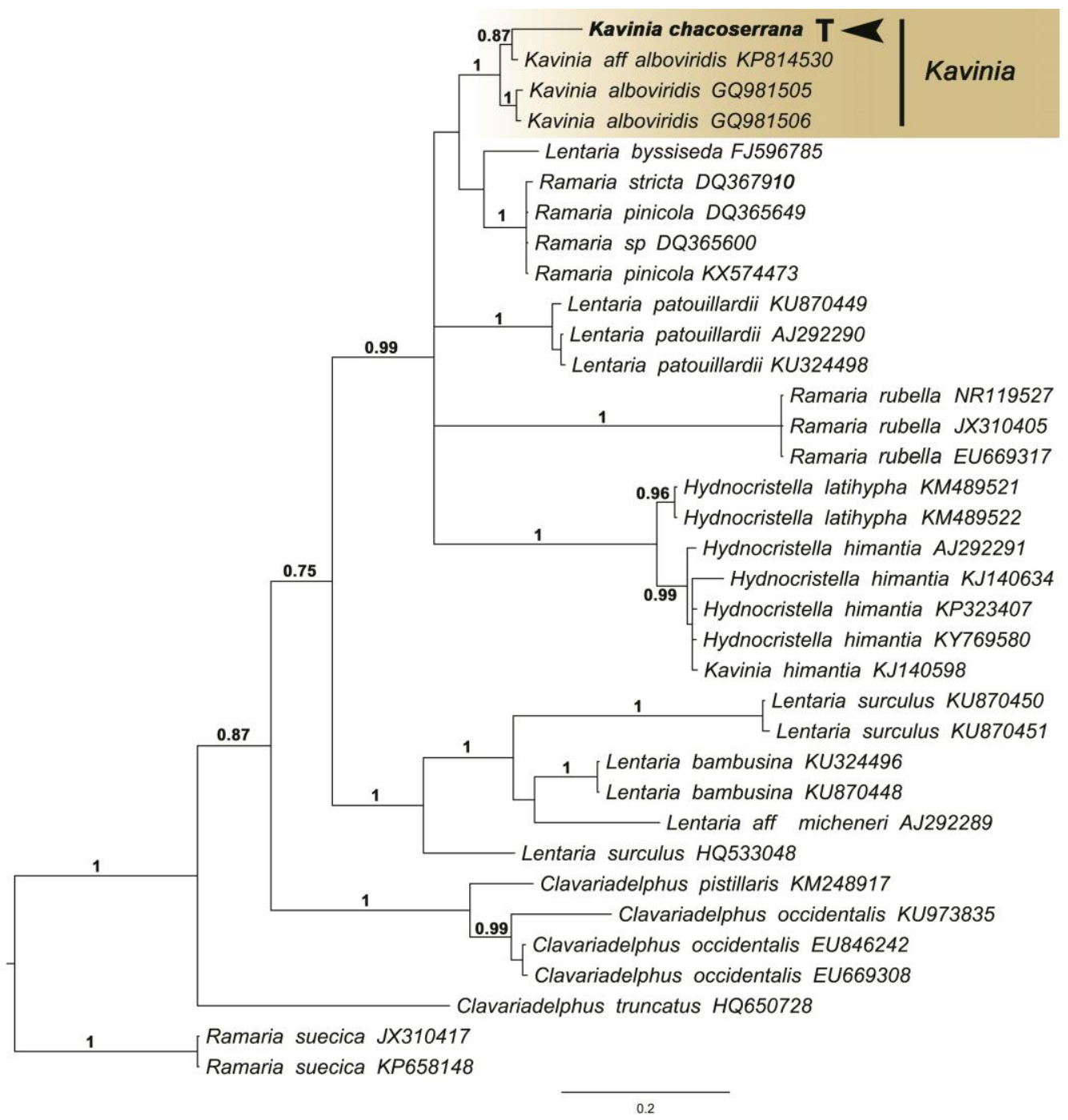

Figure 1 - Strict consensus tree from Bayesian inference of the combined ITS dataset. $\mathbf{T}<=$ type specimen. 

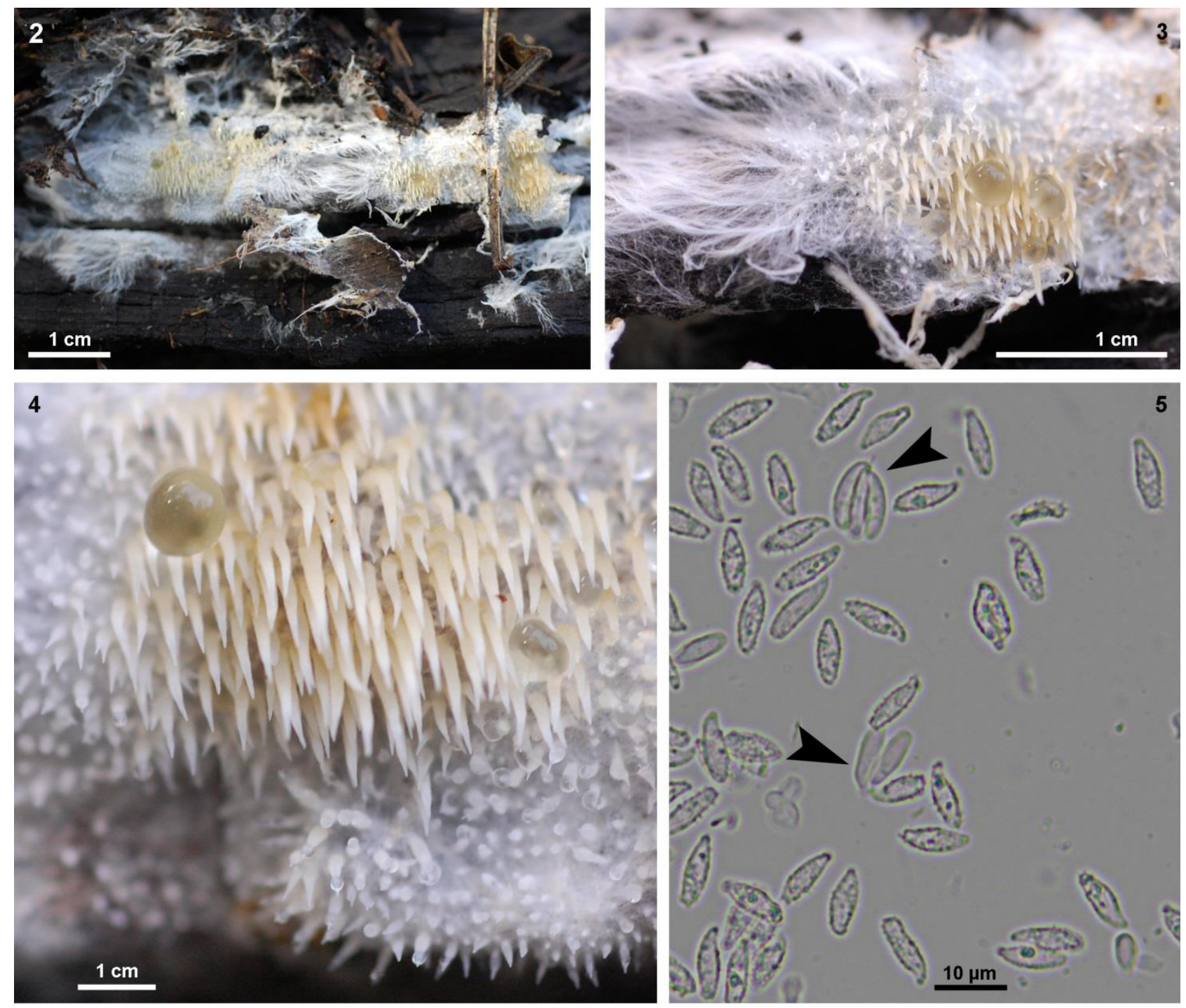

Figures 2-5 - Kavinia chacoserrana (Robledo 2516 CORD Holotype). 2-4 Macromorphological characters. 2 General view in situ. 3 Close-up of margin showing rhizomoprhs. 4 Detail of the spiny hymenophore. 5 Basidiospores. Black arrows (<) indicate tetrads of basidiospores. These pictures are copyright of Gerardo Robledo.

\section{Annotated Key to Kavinia and Hydnocristella species}

1. Basidiospores smooth, $\mathrm{CB}-$.....

2 Hydnocrystella

1'. Basidiospores verrucose, $\mathrm{CB}+$ 3 Kavinia

2. Basidiospores $8-10 \mu \mathrm{m}$ long H. hymantia

2'. Basidiospores 10-12 $\mu \mathrm{m}$ long H. latihypha

3. Basidiospores fusiform 4

3'. Basidiospores globose to ellipsoid 5

4. Basidiospores $8-9 \times 3.5-4.5 \mu \mathrm{m}$; hymenophore typically olive green K. albo-viridis

4'. Basidiospores 10-12 $\times 3-4 \mu \mathrm{m}$; hymenophore white to pale yellowish. K. chacoserrana

5. Basidiospores globose to subglobose K. globispora

5'. Basidiospores ellipsoid or subamygdalyform 6

6. Basidiosopres ellipsoid K. salmonea 6'. Basidiospreos subamygdalyform K. vivantii 


\section{Discussion}

Macroscopically Kavinia chacoserrana differs from the other species in the genus by developing resupinate basidiomata with a white to pale yellowish hydnoid hymenophore. Microscopically is distinguished by cylindrical to fusiform basidiospores. Morphologically, $K$. chacoserrana strongly resembles $K$. alboviridis, the only other species of the genus that has fusiform to subfusiform basidiospores, but the hymenophore is olive green in $K$. alvoviridis, whereas is white to pale yellowish in $K$. chacoserrana.

Phylogenetically Kavinia chacoserrana is related to $K$. alvoviridis, the only other species with sequences available. Our analysis showed that $K$. alvoviridis seem to encompass at least two species. Two specimens coming from Europe (England) confirm a phylogenetic species. Another specimen, identified at Genbank as $K$. aff. alboviridis coming from North America, is closer related to $K$. chacoserrana. This evidence, support the idea suggested by Kout \& Hajšmanová (2015) that more than one species is involved under the name.

Kavinia bourdotii (Bres.) Pilat, a species described from France with basidiospores 6-8 $\times 2.75$ 3.5 (Bresadola 1908) and currently under synonymy of $K$. alboviridis, is a name that could be applied to European specimens. The type specimen of K. alboviridis comes from Miami Valley, Ohio, USA (Morgan 1887) and is the prevailing name for specimens of North America. Further molecular evidence is desirable to resolve the taxonomical status of $K$. alboviridis and its synonyms.

\section{Acknowledgements}

Authors wish to acknowledge the assistance of the Consejo Nacional de Investigaciones Científicas y Técnicas (CONICET) and the Universidad Nacional de Córdoba, both of which support facilities used in this project. Financial support was provided by FONCYT (PICT 1676) and Fondo IBOL Conicet to C. Urcelay; and by FONCYT (PICT-2015-0830) to G. Robledo. Agencia Cordoba Ambiente gaves permissions to work in protected areas. Authors kindly acknowledged A. Bringas, curator of CORD, for providing the collections necessary for this study; Idea Wild for their support with technical equipment; and Dr. E.M. Grassi, G. Bertone, L. Caeiro and D. Franchi for their technical support

\section{References}

Bitew A, Ryvarden L. 2011 - Preliminary check-list of wood inhabiting Basidiomycetes of Ethiopia. Synopsis Fungorum 29, 11-21.

Boidin J, Gilles G. 2000 - Le genre Kavinia Pilat (Basidiomycotina). Cryptogamie Mycologie 21, 139-143.

Bresadola G. 1908 - Fungi aliquot Gallici novi vel minus cogniti. Annales Mycologici 6, 37-47.

Chen J, Shen L, Cui B. 2015 - Morphological characters and molecular data reveal a new species of Hydnocristella (Gomphales, Basidiomycota) from southwestern China. Nova Hedwigia 101, 139-146.

Dai YC. 2011 - A revised checklist of corticioid and hydnoid fungi in China for 2010. Mycoscience $52,69-79$.

Darriba D, Taboada GL, Doallo R, Posada D. 2012 - jModelTest 2: more models, new heuristics and parallel computing. Nature Methods 9, 8-772.

Dentinger BTM, Margaritescu S, Moncalvo JM. 2010 - Rapid and reliable high-throughput methods of DNA extraction for use in barcoding and molecular systematics of mushrooms. Molecular Ecology Resources 10, 628-633.

Doğan HH. 2009 - Two new lignicolous fungi additions to turkey mycota. SDU Journal of Science 4, 5-39.

Eriksson J, Ryvarden L. 1976 - The Corticiaceae of North Europe 4: Hyphodermella - Mycoacia. Fungiflora, Oslo, pp. 549-886. 
Ferreira-Lopes V, Robledo GL, Reck MA, Góes-Neto A., Drechsler-Santos E.R. 2016 - Phylloporia spathulata sensu stricto and two new South American stipitate species of Phylloporia (Hymenochaetaceae). Phytotaxa 257, 133-148.

Giachini AJ, Hosaka K, Noura ER, Spatafora JW, Trappe JM. 2010 - Phylogenetic relationships of the Gomphales based on nuc- 25S-rDNA, mit-12S-rDNA and mit-ATPg-DNA combined sequences. Fungal Biology 114, 224-234.

Gilbertson RL, Budington AB. 1970 - New records of Arizona wood-rotting fungi. Journal of the Arizona Academy of Sciences 6, 91-97.

Gómez-Montoya N, Drechsler-Santos ER, Ferreira Lopes V, Tomšovský M et al. 2017 - New insights on Trametopsis Tomšovský (Polyporales Gäum) based on phylogenetic evidences and morphological analyses of neotropical species. Phytotaxa (In press).

Greslebin A. 2002 - Fungi, Basidiomycota, Aphyllophorales: Coniophoraceae, Corticiaceae, Gomphaceae, Hymenochaetaceae, Lachnocladiaceae, Stereaceae, Thelephoraceae. Tulasnellales: Tulasnellaceae. Flora Criptogámica de Tierra del Fuego 11(4). pp. 1-212.

Katoh K, Standley DM. 2013 - MAFFT. Multiple sequence alignment software 7: improvements in performance and usability. Molecular Biology and Evolution 30, 772-780.

Kout J, Hajšmanová P. 2015 - Kavinia alboviridis in the Czech Republic. Czech Mycology 67, 5967.

Maekawa N, Yang ZL, Zang M. 2002 - Corticioid fungi (Basidiomycetes) collected in Sichuan Province, China. Mycotaxon 83, 81-95.

Morgan AP. 1887 - The mycologic flora of the Miami Valley, Ohio. Journal of the Cincinnati Society of Natural History 10, 7-18.

Natarajan K; Kolandavelu K. 1985 - Kavinia globispora sp. nov. Transactions of the British Mycological Society 84, 362-363.

Rattan S. 1977 - The resupinate Aphyllophorales of the North-Western Himalayas. Bibliotheca Mycologica 60. Ed. J. Cramer, Vaduz. pp. 1-427.

Ronquist F, Teslenko M, Van der Mark P, Ayres DL et al. 2011 - MRBAYES 3.2: efficient Bayesian phylogenetic inference and model choice across a large model space. Systematic Biology 61, 539-542.

Tamura K, Stecher G, Peterson D, Filipski A, Kumar S. 2013 - MEGA 6: Molecular Evolutionary Genetics Analysis Version 6.0. Molecular Biology and Evolution 30: 2725-2729.

Thiers B. 2017 - (continuously updated). Index Herbariorum: a global directory of public herbaria and associated staff. New York Garden's Virtual Herbarium. In: New York Garden's Virtual Herbarium. Available from http://sweetgum.nybg.org/ih/ (accessed 24 Jun 2017). 